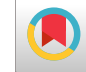

\title{
Predictive Genetic Testing for Hereditary Cancers in Children: An Argumentation
}

\author{
Hazem Al Azzam ${ }^{1}$, Majd T. Mrayyan ${ }^{2,{ }^{*}}$, Khloud Al Dameery ${ }^{3}$ and Omar Al Omari ${ }^{3}$ \\ ${ }^{1}$ Royal Medical Services, Amman, Jordan \\ ${ }^{2}$ Faculty of Nursing, The Hashemite University, Zarqa, Jordan \\ ${ }^{3}$ Faculty of Nursing, Sultan Qaboos University, Muscat, Oman \\ "Corresponding author: Faculty of Nursing, The Hashemite University, Zarqa, Jordan. Tel: +96-253903333, Email: mmrayyan@hu.edu.jo
}

Received 2019 January 10; Revised 2019 May 29; Accepted 2019 October 05.

\begin{abstract}
Context: Whether predictive genetic testing should be used on children to detect inherited cancers is one of the common debates in the medical field. This is an emerging and escalating issue related to the advancement of medical technologies and sciences.

Objectives: To advocate the predictive genetic testing of children to detect inherited cancers from the ethical and legal perspectives of both proponents and opponents.

Conclusions: Various opinions about the predictive genetic testing of children to detect inherited cancers were discussed; this will help healthcare providers to stand on firm ground regarding the current issue. Many of the ethical and legal issues noted by both proponents and opponents were discussed. Common ethical concerns are children's autonomy versus the parents' rights to decide, health insurance, genetic discrimination, and whether the benefits outweigh the risks of testing. There are many laws to protect children's welfare in areas related to genetic discrimination, children's autonomy, and health insurance; however, many organisations defer the genetic testing of children until adulthood, especially if there are no clear medical benefits. The authors are proponents for the genetic testing of children in order to detect inherited cancers. More efforts are needed in the areas of healthcare procedures, legislation, disease prevention, and community awareness when it comes to fighting cancers.
\end{abstract}

Keywords: Predictive, Genetic Testing, Inherited Cancers, Children, Ethics, Laws

\section{Context}

Predictive genetic testing is used to anticipate the occurrence of a particular disease or specific cancer in the future $(1,2)$. A hereditary cancer is any type of cancer caused by congenital gene mutation that may transfer from one generation to another (1). Patients with hereditary cancers are exposed to recurrent or secondary cancers, and their family members are also exposed to the same gene mutation (2). Hereditary cancers account for approximately $5 \%$ to $10 \%$ of all cancers (1). Most cancers start due to gene mutations that take place sometime during a person's lifetime, and thus the detection of these gene mutations requires an examination of the structure of chromosomes and genes (2).

Globally, the genetic testing of children is one of the most debated medical subjects; it has been charged with controversy since the 1960s (3). Predictive genetic testing to predict the future risk of developing cancer depends on an individual's autonomy. Individuals themselves should choose whether they want to know their risk of cancers or not (2). However, the situation regarding the predictive ge- netic testing of children is still controversial. There are various debates about the benefits and risks of these tests for this age group and whether these tests can be delayed until adulthood (3). It is also debated whether guardians have the right to decide whether their children undergo testing or not (3). Other debates include when, how and under what circumstances children should undergo testing and revolve around stigmatisation, confidentiality, and genetic discrimination (3-6). The purpose of the current paper is to present the viewpoints of proponents and opponents from both ethical and legal perspectives to support the current authors' position on the topic. The current authors support predictive genetic testing among children in order to predict inherited cancers.

\section{Ethical Arguments Regarding the Predictive Genetic Testing of Children to Detect Hereditary Cancers}

\subsection{Proponents' Perspectives}

Professional organisations worldwide support the predictive genetic testing of children to detect conditions that they may develop in the future (7). The American Society 
of Clinical Oncology (ASCO) has played a significant role in raising the awareness of healthcare providers, including oncologists, regarding the importance of detecting the risks of hereditary cancers in the field of oncology and in primary cancer prevention settings (8). Predictive genetic testing is recommended for a child with a positive hereditary family history of a specific genetic cancer, especially if early detection or therapeutic interventions may affect morbidity or mortality rates $(3,9)$.

The predictive genetic testing of children to detect heredity cancers helps in understanding the risk of getting a particular cancer, to make appropriate decisions about a person's future health, and to decrease the risk of cancers by changing unhealthy habits and modifying life styles (2, 10). Predictive genetic testing has a pivotal role in the early detection and early treatment of cancer and will also alleviate anxiety and stress if the result of the test is negative (46). Genetic testing will help healthcare providers with regard to the prevention and early detection of cancers, treatment procedures, diagnosis and prognosis of the disease, the development of pharmacogenomics, and lifesaving decisions if a test result is positive (3).

Annually, around four million infants undergo newborn screening to identify various abnormalities in the United States of America (USA) alone, for which early detection and early treatments are promoted, which will help in preventing or minimising morbidity and mortality rates (11). Predictive genetic testing and its role in reducing morbidity and mortality faces many barriers that should be tackled (3). Parents should be educated about the process and the goals of these tests so that they are able to decide about the genetic testing of their children (3). Multiple factors regarding whether predictive genetic testing should be performed have to be considered in order to make the best decision for the child; the most important factor is the welfare of the child's future (12). Parents, genetic counsellors, social workers, and healthcare providers should thus be involved in providing information to help decisionmaking about predictive genetic testing for a child $(10,12)$.

In the United Kingdom (UK), $47 \%$ of participants agreed on the rights of parents to decide upon the genetic testing of their children, regardless of whether there are therapeutic interventions or not, and $60 \%$ agreed that it was the parents' choice whether to test their children, regardless of whether they were carriers of a genetic disease or not (7). It could be explained to parents that they may be able to do something based on the test's results, such as changing lifestyles, being alerted to symptoms and interventions, and preparing themselves and their children to adapt to the situation. From both an ethical and legal viewpoint, parents should therefore be involved in deciding about the genetic testing of their children, because this test may have psychological and social impacts for all family members (4-6). Parents should seek more informa- tion regarding their children's risks of developing inherited cancers and the need to detect any hereditary cancer early before it starts; this will improve the chance of preventing cancers and minimise the risks (13). Where there is debate between parents and healthcare providers about performing this test, especially when the parents are reluctant to test their children and ignore the advice of healthcare providers, those providers could argue in the court that the parents' decision was abusive and negligent to their children's health (3).

\subsection{Opponents' Perspectives}

There are various problems surrounding the predictive genetic testing of children, and these should be considered before undergoing this test. One of these problems is the limited answers provided; a genetic test does not always give precise answers about inherited cancers, such as breast and colon cancers. This test is as susceptible to errors as any other test (i.e., false positives and false negatives), which may lead to physical and psychosocial harm, in addition to the loss of children's privacy (2). Another problem is when parents react to the results by trying unverified treatments or preventive measures with significant adverse effects; for example, giving extra doses of vitamin A to children with developmental disabilities without respect to its serious adverse effects, such as liver toxicity $(14,15)$.

The most common explanation given by healthcare providers for not advocating genetic tests is that they wish to protect the child's future autonomy (12). In the UK, the law recognises children's future autonomy without looking to claim for the parents to find out a family history regarding genetic status, except if there are clear-cut benefits from the test for the child (16). Predictive genetic testing should be delayed until adulthood unless therapeutic interventions in the childhood period will reduce rates of morbidity or mortality $(7,13,17)$. Twenty percent of participants disagreed with the statement that parents have the right to decide whether to perform genetic testing of their children (7). The most common explanation given for delaying the test until adulthood is a worry about the child being misinformed, because they are not involved in the decision-making from the beginning. Also, a fear that the child will suffer from discrimination, and parents are acting in ignorance of the child's autonomy in the future.

Positive predictive genetic testing for serious inherited cancers may potentially cause psychological problems, such as anxiety, altered self-image, changed perceptions of the child, feelings of guilt, ineffective coping methods, stress in the family, depression, and social isolation $(3-6,18)$, although there is a dearth of studies that have explored the effect of genetic testing for untreatable illnesses on the psychology of children $(19,20)$. Furthermore, as a reaction to the results, children may adopt a new lifestyle, 
for example, refraining from eating certain types of food and/or avoidance of prolonged, unnecessary exposure to the sun to prevent or minimise the occurrence of cancer $(21,22)$. To further complicate matters, this test may also lead to serious physical harms as a result of making drastic decisions, such as prophylactic mastectomy, based on inaccurate test results (13).

\section{Legal Arguments Regarding the Predictive Genetic Testing of Children to Detect Hereditary Cancers}

\subsection{Proponents' Perspectives}

In various countries, laws regulate the predictive genetic testing of children to detect hereditary cancers $(4,5$, 11). These laws aim to protect the child's welfare, especially in areas related to genetic discrimination, the child's autonomy, and health insurance $(4,5)$.

The United States Professional Guidelines (2013) and the United Kingdom Guidelines presented by the British Society of Human Genetics (BSHG) (2010) adopted the same opinion on genetic testing, which is that this test should be performed based on the children's best interests. Both countries allow parents, children, physicians, and the courts to participate in the decision-making process related to predictive genetic testing (3). A recent qualitative study explored children's perspectives toward genetic testing. The result showed that children preferred to have genetic testing, but they still valued their parents' opinions and consent about it (23).

There are many laws to regulate genetic testing in many states in the USA, including Alabama, Connecticut, Michigan, New York, and California (8). In Switzerland, a law was passed in 2007 to regulate the predictive genetic testing of children, which gives parents the right to decide about genetic testing for their children (24). The law penalises parents who neglect to undertake genetic testing for their children, especially if there is a positive family history, resulting in imprisonment or a fine. In Spain, the Committee of Ministers of the Council of Europe decided in April 1997, in Article (6), to give parents the right to make decisions for their children.

In the Arab world, the subject of genetic testing is not yet regulated, except in Lebanon (Law No. 625 of 2004) (25). Other countries have ignored this issue completely or regulated it partially by using institutionalised guidelines and policies. In Jordan, there are no regulations on this issue, except that the Institutional Review Board (IRB) regulates genetic testing (25). In Jordan, genetic tests for minors and disabled people are permitted after obtaining informed consent from their legal guardians.

Genetic tests for insurance and employment purposes are prohibited in some countries (25). In order to preserve the rights of children and encourage parents to perform genetic testing of their children, national law in the USA protects children's rights by prohibiting discrimination due to genetic tests and keeping health insurance active, even if a result is positive, and preserving the confidentiality of genetic testing information through the Genetic Information Non-discrimination Act (GINA) of 2008 (2).

\subsection{Opponents' Perspectives}

The American College of Medical Genetics defers the genetic testing of children until adulthood if there are no clear medical benefits (17). The Guidelines of the European Society of Human Genetics also suggest that paediatric predictive genetic testing should only be performed if there are clear benefits, especially in late-onset conditions (16). The American College of Medical Genetics and Genomics (ACMG) and American Academy of Paediatrics (AAP) are against the predictive genetic testing of minors, because this test does not offer health benefits in the childhood period and exempt from previous is having an intervention in childhood that impacts their future morbidity or mortality (11, 26-28). According to the Clinical Genetics Society in the UK, the genetic testing of children to predict hereditary diseases should not be carried out until children requests such tests for themselves (11).

In summary, the predictive genetic testing of children to detect hereditary cancers is debatable, ethically and legally. From an ethical perspective, one of the most important debates is whether the test offers clear benefits or not, whether this test will help children in the prevention and treatment of the disease or not, and when to do this test. Another important debate is the balance between benefits and risks, the burdens of this test on the child and on families, and whether parents have the right to decide whether to perform this test on their children or delay it until adulthood to preserve the children's future autonomy. Finally, there is always the fear of discrimination due to genetic tests, such as the health insurance of children who undergo this test being cancelled, particularly where there are positive results regarding inherited cancers. From a legal perspective, many laws in various countries protect children's welfare, especially in areas related to genetic discrimination, children's autonomy, and health insurance. Many organisations defer the genetic testing of children until adulthood if there are no clear immediate medical benefits.

\section{Current Researchers' Argumentative Statement}

The predictive genetic testing of children to detect inherited cancers is one of the hot topics of the current medical era. Various ethical and legal questions have been raised about this testing (4-6). The current authors support the predictive genetic testing of children for the early detection of hereditary cancers; this test will minimise a child's suffering if they are at risk for cancer. This test helps 
to prevent cancers and contributes to the optimal management of this disease. It will also probably help the next generation to avoid cancer gene mutations and will also help pharmacists to develop more effective cancer drugs with less adverse effects.

The current researchers are also proponents of the predictive genetic testing of children from an ethical perspective, as it helps healthcare providers in the prevention, early detection and treatment of cancers as well as helps children and their parents to adopt lifesaving decisions in the case of positive results for hereditary cancers $(4-6,29)$. Predictive genetic testing for therapeutic purposes is not prohibited under the Islamic religion; genetic engineering plays an important role in the prevention of diseases, in treatments, and in lessening the damage of various genetic diseases.

We are also proponents of the predictive genetic testing of children from a legal perspective, taking into consideration all the legal rights of children in order to protect them against genetic discrimination and discrimination in all its forms (2).

\section{Summary and Conclusions}

The predictive genetic testing of children to detect hereditary cancers is controversial. The purpose of this argumentative paper was to present the viewpoints of proponents and opponents from the ethical and legal perspectives.

Common elements of debate include the children's autonomy versus the parents' rights to decide, health insurance, genetic discrimination, and whether the benefits outweigh the risks.

Various laws and organisations protect children's welfare in areas related to genetic discrimination, children's autonomy, and health insurance; however, many organisations oppose the genetic testing of children; they suggest postponing it until adulthood if there are no clear medical benefits. The current authors support the predictive genetic testing of children to detect hereditary cancers as early as possible.

\section{Footnotes}

Authors' Contribution: Hazem Al Azzam has the idea and searched the databases for references and worked an initial draft of the paper. Majd T. Mrayyan organized the literature review and prepared the first draft and supervised the whole work and worked as the corresponding author and fixed reviewers' comments in coordination with Omar Al Omari. Khloud Al Dameery revised the first draft and prepared the communication with the journal and submitted the paper. Omar Al Omari revised the whole paper for consistency and first edited the paper and the communicated with a company for proof reading of the paper, and worked on the reviewers' comments with Majd T. Mrayyan.

Conflict of Interests: The authors have no conflict of interests.

Funding/Support: The authors have no funding/support.

\section{References}

1. Rew L, Kaur M, McMillan A, Mackert M, Bonevac D. Systematic review of psychosocial benefits and harms of genetic testing. Issues Ment Health Nurs. 2010;31(10):631-45. doi: 10.3109/01612840.2010.510618. [PubMed: 20854036].

2. American Cancer Society. Understanding genetic testing for cancer. 2013, [cited 13th December]. Available from: https: //www.cancer.org/cancer/cancer-causes/genetics/understandinggenetic-testing-for-cancer.html.

3. Ross LF. Predictive genetic testing of children and the role of the best interest standard. J Law Med Ethics. 2013;41(4):899-906. doi: 10.1111/jlme.12099. [PubMed: 24446947].

4. Botkin JR, Belmont JW, Berg JS, Berkman BE, Bombard Y, Holm IA et al. Points to consider: Ethical, legal, and psychosocial implications of genetic testing in children and adolescents. Am J Hum Genet. 2015;97(1):6-21. doi: 10.1016/j.ajhg.2015.05.022. [PubMed: 26140447]. [PubMed Central: PMC4570999].

5. Mand C, Gillam L, Delatycki MB, Duncan RE. Predictive genetic testing in minors for late-onset conditions: A chronological and analytical review of the ethical arguments. JMed Ethic. 2012;38(9):519-24. doi: 10.1136/medethics-2011-100055.

6. Wahidi L, Brandt L, Sherman J, Sherman M. Case analysis: Ethical issues in predictive genetic testing of minors for adult-onset hereditary conditions. J Acad Hospital Med. 2015;7(2).

7. Shkedi-Rafid S, Fenwick A, Dheensa S, Lucassen AM. Genetic testing of children for adult-onset conditions: Opinions of the British adult population and implications for clinical practice. Eur J Hum Genet 2015;23(10):1281-5. doi: 10.1038/ejhg.2014.221. [PubMed: 25370041]. [PubMed Central: PMC4592073].

8. Robson ME, Storm CD, Weitzel J, Wollins DS, Offit K; American Society of Clinical Oncology. American Society Of Clinical Oncology policy statement update: Genetic and genomic testing for cancer susceptibility. J Clin Oncol. 2010;28(5):893-901. doi: 10.1200/JCO.2009.27.0660. [PubMed: 20065170].

9. United Health Care Services. Genetic testing for hereditary cancer: United Healthcare commercial medical policy. 2018, [cited 20 Novmber]. Available from: https://www.uhcprovider.com/content/ dam/provider/docs/public/policies/comm-medical-drug/genetictesting-hereditary-breast-ovarian-cancer-syndrome.pdf.

10. Druker H, Zelley K, McGee RB, Scollon SR, Kohlmann WK, Schneider $\mathrm{KA}$, et al. Genetic counselor recommendations for cancer predisposition evaluation and surveillance in the pediatric oncology patient. Clin Cancer Res. 2017;23(13):e91-7. doi: 10.1158/1078-0432.CCR-17-0834. [PubMed: 28674117].

11. Committee On Bioethics; Committee On Genetics A. N. D; American College Of Medical Genetics A. N. D; Genomics Social; Eth ical Legal Issues Committee. Ethical and policy issues in genetic testing and screening of children. Pediatrics. 2013;131(3):620-2. doi: 10.1542/peds.2012-3680. [PubMed: 23428972].

12. Dewell C. If it's only a blood test, which isn't very traumatic, why not? exploring predictive genetic testing in adoption. Adopt Foster 2012;36(3-4):133-6. doi: 10.1177/030857591203600316.

13. Tarini BA, Tercyak KP, Wilfond BS. Commentary: Children and predictive genomic testing: Disease prevention, research protection, and our future. J Pediatr Psychol. 2011;36(10):1113-21. doi: 10.1093/jpepsy/jsro40. [PubMed: 21816897]. [PubMed Central: PMC3199444]. 
14. Ross LF, Saal HM, David KL, Anderson RR; American Academy of Pediatrics; American College of Medical Genetics. Technical report: Ethical and policy issues in genetic testing and screening of children. Genet Med. 2013;15(3):234-45. doi: 10.1038/gim.2012.176. [PubMed: 23429433].

15. Listernick R. A 30-month-old boy with developmental regression and hepatosplenomegaly. Pediatr Ann. 2003;32(8):500-3. doi: 10.3928/0090-4481-20030801-06. [PubMed: 12942891].

16. Lucassen A. Report on the genetic testing of children. Birmingham;2010.

17. Caga-anan EC, Smith L, Sharp RR, Lantos JD. Testing children for adult-onset genetic diseases. Pediatrics. 2012;129(1):163-7. doi 10.1542/peds.2010-3743. [PubMed: 22144703].

18. Evers-Kiebooms G, Denayer L. Predictive genetic testing: Psychological impact. Encyclopedia of life sciences. Wiley; 2008. doi: 10.1002/9780470015902.a0005631.pub2.

19. Wakefield CE, Hanlon LV, Tucker KM, Patenaude AF, Signorelli C, McLoone JK, et al. The psychological impact of genetic information on children: A systematic review. Genet Med. 2016;18(8):755-62. doi 10.1038/gim.2015.181. [PubMed: 26741411].

20. Vetsch J, Wakefield CE, Warby M, Tucker K, Patterson P, McGill BC, et al. Cancer-related genetic testing and personalized medicine for adolescents: A narrative review of impact and understanding. J Adolesc Young Adult Oncol. 2018;7(3):259-62. doi: 10.1089/jayao.2017.0102. [PubMed: 29336661].

21. Villani A, Shore A, Wasserman JD, Stephens D, Kim RH, Druker H, et al. Biochemical and imaging surveillance in germline TP53 mutation carriers with Li-Fraumeni syndrome: 11 year follow-up of a prospective observational study. Lancet Oncol. 2016;17(9):1295-305. doi:10.1016/S1470-2045(16)30249-2. [PubMed: 27501770].

22. Villani A, Tabori U, Schiffman J, Shlien A, Beyene J, Druker H, et al Biochemical and imaging surveillance in germline TP53 mutation carriers with Li-Fraumeni syndrome: A prospective observational study. Lancet Oncol. 2011;12(6):559-67. doi:10.1016/S1470-2045(11)70119X. [PubMed: 21601526].

23. Alderfer MA, Lindell RB, Viadro CI, Zelley K, Valdez J, Mandrell B, et al. Should genetic testing be offered for children? The perspectives of adolescents and emerging adults in families with Li-Fraumeni syndrome. J Genet Couns. 2017;26(5):1106-15. doi: 10.1007/s10897-017-0091x. [PubMed: 28303452].

24. The Federal Assembly of the Swiss Confederation. Federal law on human genetic testing Switzerland. 2014, [cited 13th December]. Available from: https://www.admin.ch/opc/en/classified-compilation/ 20011087/201401010000/810.12.pdf.

25. Boustany FN. Report of mapping bioethics regulations in 17 states in the Arab region, ethics and law in biomedicine and genetics. 2011.

26. American College of Medical Genetics AND; Committee on Bioethics; Committee on Genetics; Genomics Social Ethical Legal Issues Committee. Ethical and policy issues in genetic testing and screening of children. Pediatrics. 2013;131(3):620-2. doi: 10.1542/peds.2012-3680. [PubMed: 23428972].

27. Clayton EW, McCullough LB, Biesecker LG, Joffe S, Ross LF, Wolf $\mathrm{SM}$, et al. Addressing the ethical challenges in genetic testing and sequencing of children. Am J Bioeth. 2014;14(3):3-9. doi: 10.1080/15265161.2013.879945. [PubMed: 24592828]. [PubMed Central: PMC3950962].

28. Arbour L, Canadian Paediatric Society; Bioethics Committee. Guidelines for genetic testing of healthy children. Paediatr Child Health. 2003;8(1):42-52. doi: 10.1093/pch/8.1.42. [PubMed: 20011555]. [PubMed Central: PMC2791077].

29. Ross LF, Saal HM, David KL, Anderson RR. Technical report: Ethical and policy issues in genetic testing and screening of children. Genetics in Medicine. 2013;15(3):234. 